\title{
Prescribing knowledge in the light of undergraduate clinical pharmacology and therapeutics teaching in India: views of first-year postgraduate students
}

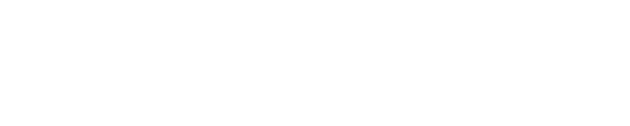

Prerna Upadhyaya'

Vikas Seth ${ }^{2}$

Monika Sharma'

Mushtaq Ahmed'

Vijay Vasant Moghe'

Zafar Yab Khan'

Vinay Kumar Gupta'

Shipra Vikram Jain'

Utkarsh Soni'

Manohar Bhatia'

Kumar Abhijit'

Jaswant Goyal'

'Department of Pharmacology, Mahatma Gandhi Medical College, Jaipur, ${ }^{2}$ Department of Pharmacology, Hind Institute of Medical Sciences, Lucknow, India
Correspondence: Prerna Upadhyaya, Department of Pharmacology, Mahatma Gandhi Medical College, Sitapura, Jaipur 302022, India

Tel +9| 998333362 I

$\mathrm{Fax}+91$ | 412770900

Email drprerna@rediffmail.com
Objectives: The study aimed to review the prescribing knowledge of first-year postgraduate doctors in a medical college in India, using the principles of good prescribing, to suggest strategies to improve rational prescribing, and to recommend what curriculum planners can do to accomplish this objective.

Methods: Fifty first-year postgraduate doctors were asked to fill in a structured questionnaire that sought information regarding their undergraduate training in clinical pharmacology and therapeutics, prescribing habits, and commonly consulted drug information sources. Also, the questionnaire assessed any perceived deficiencies in their undergraduate clinical pharmacology teaching and sought feedback regarding improvement in the teaching.

Results: Eighty-eight percent of residents said that they were taught prescription writing in undergraduate pharmacology teaching; $48 \%$ of residents rated their prescribing knowledge at graduation as average, $28 \%$ good, $4 \%$ excellent, $14 \%$ poor, and $4 \%$ very poor; $58 \%$ felt that their undergraduate training did not prepare them to prescribe safely, and $62 \%$ felt that their training did not prepare them to prescribe rationally. Fifty-eight percent of residents felt that they had some specific problems with writing a prescription during their internship training, while $92 \%$ thought that undergraduate teaching should be improved. Their suggestions for improving teaching methods were recorded.

Conclusions: This study concludes that efforts are needed to develop a curriculum that encompasses important aspects of clinical pharmacology and therapeutics along with incorporation of the useful suggestions given by the residents.

Keywords: clinical pharmacology and therapeutics, medical education, prescription writing, undergraduate medical curriculum, pharmacovigilance, pharmacoeconomics

\section{Introduction}

Pharmacology is a crucial branch of the medical college curriculum, endowing medical students with knowledge about drugs. It is imperative that medical students appreciate the importance of pharmacology and apply that knowledge appropriately in their future practice as doctors. ${ }^{1}$ Pharmacology should aim to produce rational prescribers rather than churning out confused practitioners in a therapeutic jungle. Traditional forms of pharmacology teaching take place through didactic lectures and are more teacher centered, with emphasis on learning the facts and figures of drugs. ${ }^{2}$ Constant review of the teaching and evaluation methods through feedback 
from students and modification of the methodologies is very important for planning the undergraduate medical curriculum. ${ }^{3}$

Clinical pharmacology and therapeutics (CPT) envisages undergraduate (UG) medical students being able to plan, select, communicate, and guide patients throughout their illness to use medicines and other devices. The main goal of CPT is to impart knowledge, skills, and attitudes so that a student is able to weigh the potential benefits and risks of treatment along with cost-effectiveness, understand the sources of variability in responses to medicine, base prescribing decisions on sound evidence, and monitor medicine effects appropriately. ${ }^{4} \mathrm{CPT}$ has been integrated progressively into the UG curricula of many countries, such as the US, UK, India, Nepal, and the Netherlands, to pave the way to improvement in the prescribing knowledge and skills of doctors. ${ }^{5-9}$

The majority of prescription-related errors in hospitals are due to poor prescribing by junior doctors. ${ }^{10}$ Due to changes in medical education in the last 20 years, an overburdened curriculum, and lack of focus on social sciences, there is less teaching in UG CPT. Also, the process of prescribing has become more and more difficult, with more potent drugs available in the market, aging populations, and the frequent need for polypharmacy. System analysis shows that knowledge and training are relevant factors in causation and focused education will improve prescribing performance. ${ }^{11}$ There is a need to educate UG students and develop methods to improve their prescription knowledge. ${ }^{12,13}$ This study reviews the prescribing knowledge of first-year doctors of the principles of good prescribing. Also, strategies to improve rational prescribing are suggested, and recommendations made on what curriculum planners and policy-makers can do to accomplish this objective.

\section{Materials and methods}

This was a cross-sectional, questionnaire-based study. The study was done in a private teaching tertiary care hospital in Rajasthan - Mahatma Gandhi Medical College and Hospital, Jaipur, India. Approval was received from the institutional ethics committee. Subjects were drawn from first-year postgraduate students who were pursuing their studies in any of the medical, surgical, paraclinical, and preclinical branches of medical science. Those in the first month of their course and willing to participate in the study were selected. In India, postgraduate students are selected based on a national level exam after completing their graduation and internship. After selection, they choose a particular branch of preclinical, paraclinical, or clinical medicine and study for 3 years exclusively in their specialized field.

A structured questionnaire in English was designed after modifications from the work of Oshikoya et $\mathrm{al}^{14}$ and Tobaiqy et al. ${ }^{15}$ The questionnaire sought information regarding their UG training in CPT, prescribing habits, and commonly consulted drug information sources. Also, the questionnaire assessed any perceived deficiencies in their UG clinical pharmacology teaching and asked for feedback regarding improvement of UG training in CPT (Appendix). Fifty doctors were selected. The questionnaire was handed to them after explaining the purpose of the study. They were asked to fill in the questionnaire and hand it back immediately. Those who were not present in the department were contacted by phone and the questionnaire was sent to them. They were asked to hand it back the next day. If they were unable to submit it the next day, then they were contacted and asked to submit it at the earliest opportunity. There was no incentive per se given to the first-year doctors to complete the study. Results were analyzed by nonparametric statistical tests.

\section{Results \\ Knowledge of clinical pharmacology and therapeutics}

The results are shown in Table 1. According to the first-year postgraduate doctors, the major factors affecting their ability to prescribe rationally were the patient-doctor relationship, peer pressure, and medical ethics. They also encountered several problems while writing prescriptions during their internship. Some of these problems were:

Table I Knowledge of undergraduate clinical pharmacology and therapeutics (CPT) teaching in first-year postgraduate students

\begin{tabular}{lll}
\hline Questions & Responses & $\%$ \\
\hline Were you taught prescription writing & Yes & 88 \\
in your undergraduate pharmacology? & No & 12 \\
How would you rate your prescribing & Average & 48 \\
knowledge as at graduation? & Good & 28 \\
& Excellent & 4 \\
& Poor & 14 \\
& Very poor & 4 \\
Do you feel that your undergraduate & Yes & 42 \\
training has prepared you to prescribe safely? & No & 58 \\
Do you feel that your undergraduate training & Yes & 38 \\
has prepared you to prescribe rationally? & No & 62 \\
Have you had any specific problems with & Yes & 42 \\
prescribing during your internship training? & No & 58 \\
Retrospectively, do you think undergraduate & Yes & 92 \\
CPT teaching should be improved? & No & 8 \\
\hline
\end{tabular}


- Inadequate knowledge of the brand names of drugs to be prescribed. As the teaching mostly revolves around generic names, the doctors felt at a loss when required to write brand names.

- Inadequate knowledge of fixed-dose combinations, rational or irrational.

- Lack of knowledge of newer drugs.

- In UG teaching, the main focus is on examination of the patient and diagnosing disease, rather than writing a correct prescription.

- No experience of writing prescriptions in a clinical setting.

Ninety-two percent thought that UG teaching should be improved. They were asked to suggest ways to improve the teaching methods. Their suggestions were as follows:

- Pharmacology teaching should be clinically oriented, not exam-oriented.

- The design of practical exams should be changed, with prescription writing as an integral part.

- Teaching should be more practical, with an emphasis on project work.

- Assign specific drug studies/presentations to every student.

- Teaching should be more focused on common diseases and their treatment, rather than rare diseases.

- More clinical visits to other hospitals should be arranged.

\section{Prescribing knowledge}

These results are shown in Table 2.

\section{Discussion}

This study asked first year postgraduate students to consider their prescribing knowledge in the light of undergraduate CPT teaching. They were also asked to make suggestions to improve rational prescribing and to bring about changes in CPT teaching.

The majority of students in our study acknowledged being taught about prescription writing and rated their prescribing knowledge as average. However, more students felt that UG teaching did not prepare them to prescribe rationally or safely. In a similar study conducted on foundation year 1 doctors in UK, it was found that they were unsatisfied with their UG CPT teaching and felt incapable of prescribing rationally and safely. The majority acknowledged being taught about CPT in the UG curriculum, but also felt that their prescribing knowledge was poor. ${ }^{15}$ These findings emphasize the need for improved and focused CPT teaching, with a focus on prescribing knowledge
Table 2 Prescribing knowledge of first year postgraduate students

\begin{tabular}{|c|c|c|}
\hline Questions & Responses & $\%$ \\
\hline Are you aware of the & Yes & 66 \\
\hline \multicolumn{3}{|l|}{ Essential Drugs List } \\
\hline $\begin{array}{l}\text { If yes, do you prescribe drugs according } \\
\text { to the Essential Drugs List? }\end{array}$ & Yes & 50 \\
\hline Usually you prescribe by & Generic & 66 \\
\hline which name? & Brand & 34 \\
\hline Usually in children you calculate & Age & 18 \\
\hline the doses according to the & Weight & 82 \\
\hline $\begin{array}{l}\text { Usually while prescribing, do you } \\
\text { consider the cost of the drugs? }\end{array}$ & Yes & 90 \\
\hline $\begin{array}{l}\text { Have you been taught to consider } \\
\text { the cost of the drugs? }\end{array}$ & Yes & 78 \\
\hline \multicolumn{2}{|l|}{ “pharmacoeconomics”? } & 62 \\
\hline Do you prescribe a newly & Yes & 26 \\
\hline promoted medicine? & No & 74 \\
\hline Do you prescribe supplemental & Yes & 70 \\
\hline vitamins and iron preparations? & No & 30 \\
\hline Do you prefer a fixed-dose analgesic & Combination & 48 \\
\hline combination or paracetamol? & Paracetamol & 52 \\
\hline Have you prescribed under parental & Yes & 22 \\
\hline influence even when not necessary? & No & 78 \\
\hline Do you routinely check information & Yes & 62 \\
\hline about drugs before prescribing? & No & 38 \\
\hline If the above is yes, & Product insert & 4 \\
\hline \multirow[t]{7}{*}{ which materials do you consult? } & ------------------ & \\
\hline & Internet & 20 \\
\hline & Books/journal & 26 \\
\hline & 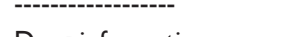 & \\
\hline & $\begin{array}{l}\text { Drug information } \\
\text { provided by the }\end{array}$ & 10 \\
\hline & medical representative & \\
\hline & $\begin{array}{l}\text { Drug information index, } \\
\text { eg, CIMS, MIMS }\end{array}$ & 40 \\
\hline
\end{tabular}

Abbreviations: CIMS, current index of medical specialities; MIMS, Monthly Index of Medical Specialities.

at UG level. A study noted that medical schools educate on the theoretical side of medicine, ${ }^{15}$ but actual prescribing in practice is very difficult. The prescribing knowledge of junior doctors needs periodic reinforcement, as suboptimal prescribing can impose a burden on society. Some medical schools in UK have introduced a e-learning toolkit called SCRIPT (Standard Computerised Revalidation Instrument for Prescribing and Therapeutics) to encourage safe prescribing. It will enable doctors to undertake basic revision and reach minimum standards in prescribing and to build upon their existing skills in safe and rational prescribing. ${ }^{16}$

In our study, the residents felt that factors that affect the ability to prescribe rationally were the patient-doctor 
relationship, peer pressure, and medical ethics. Other specific problems that affect good prescribing by a doctor are inadequate knowledge of brand names of drugs, lack of knowledge of newer drugs, no experience of writing a prescription in a clinical setting, less focus on prescription writing, and more focus on identifying disease in UG teaching. These suggest that just theoretical teaching of prescription writing and rational prescribing is not sufficient. UG teaching in CPT should stress the principle of rational evaluation of therapeutic alternatives and help the student to develop their own personal formulary on the basis of a rational comparison. Such a pattern will prevent any external disturbing factor from affecting their ability to prescribe rationally. ${ }^{17}$

In this study, the majority of students checked drug information before prescribing. The most preferred source was drug indexes, followed by books, journals, the Internet, and product inserts, while very few relied on information provided by medical representatives. There are many websites that provide information about the safe and effective use of drugs, over-the-counter medications, herbal medicines, brand names and generic names of drugs, drug interactions, and treatment options. ${ }^{18}$ Subscription sources include Medical Letter, the Drug and Therapeutic Bulletin, and the Australian Prescriber. ${ }^{19}$

The majority of doctors were aware of the Essential Drug List, while a few were not. They also prescribed drugs according to the World Health Organization Essential Drugs List. The Essential Drugs List is the foundation for every public health program aimed at reducing morbidity and mortality. It is the key strategy in helping to improve access to essential drugs and contributing to public health. Irregular access to essential medicines is an important issue in developing countries. The main causes are lack of availability, expensive drugs, no facilities or trained professionals to prescribe the drugs, inefficient pharmaceutical policies and management systems, poor funding, and bad distribution and use. ${ }^{20}$

Dosage schedules for children are usually scaled from adult dosage using body weight, body surface area, age, or by a combination of these parameters. ${ }^{21,22}$ Errors in calculating drug dosages in infants and small children can cause mortality and morbidity, especially in agents exhibiting a narrow therapeutic window. Pediatric trainees often make such mistakes, which may be life-threatening. In our study, the majority of the residents calculated children's doses according to body weight, while some used age criteria and a few surface area criteria. Some studies have reported that ongoing monitoring of prescribing abilities and introduction of e-learning resources have resulted in improvement in prescriptions. $^{23,24}$

More doctors used generic names, while fewer used brand names while writing a prescription. Generic prescribing is cost-effective and safe for the patient. It also reduces the potential for confusion and error. Generic prescribing is usually recommended for all drugs except modified-release preparations, some combination products, and drugs with a narrow therapeutic index. ${ }^{25}$

New drugs were prescribed less often than established drugs by the majority of the doctors. The majority of doctors prescribed supplemental vitamin and iron preparations. In the case of analgesics, the majority prescribe paracetamol alone, while a few prescribed a fixed-dose analgesic combination. Parental influence on doctors while writing prescriptions is a common problem, but in this study $72 \%$ doctors refused to write under parental influence. The majority of doctors considered the cost aspect of the drug, as they were taught about the pharmacoeconomics of the drug in UG teaching.

Ninety-two percent of the students felt that UG CPT teaching should be improved. They suggested ways to improve teaching methods. According to them, pharmacology teaching should be more clinically oriented rather than exam-oriented. The pattern of practical exams should be changed, with more emphasis on clinical pharmacology and prescription writing and less on pharmacy. They also felt the need to assign specific drug studies or presentations to all Bachelor of Medicine, Bachelor of Surgery students, so as to develop a clinical orientation. They also felt a need to visit other hospitals to see other cases. Emphasis should also be laid on teaching about emergency drugs, over-thecounter drugs, brand names of drugs along with generic names, doses, duration, route of administration, fixed-dose combinations, rational or irrational, newer drugs approved in the market, and antidotes used in common poisonings. UG CPT teaching should also incorporate teaching prescriptionwriting skills by making dummy prescriptions.

There are some limitations to our study. The first limitation is the small sample size, which hinders the generalization of the results to a broader community of doctors in India. Secondly, along with testing of prescribing knowledge, there should have been a practical assessment of prescription skills too. Measurement of knowledge is insufficient, an assessment of performance is also very important.

\section{Conclusions}

Teaching hospitals have a special responsibility towards promoting rational prescribing by doctors. The best way 
is to develop a hospital prescribing policy by general consensus and consultation along with involvement of clinical pharmacologists. Such prescribing policies can be integrated in the hospital formulary and can be enforced afterwards for prescribing, teaching, examinations, and medical audit. Also, there is little doubt about the importance of CPT in UG teaching. Medical graduates should be proficient in principles of rational prescribing before entering their postgraduate course. However, in India, problems are present at the stage of implementation of policies and timing of course work. Efforts are needed to develop a curriculum that encompasses theoretical teaching along with practical CPT teaching, coupled with frequent assessment of the knowledge and skills of students, which will definitely improve their rational prescribing as doctors.

\section{Disclosure}

The authors report no conflict of interest that might bias the outcome of the paper.

\section{References}

1. Rangachari PK. Basic science in an integrated medical curriculum: the case of pharmacology. Adv Health Sci Educ Theory Pract. 1997;2: 163-171.

2. Joshi MP. Problem-oriented pharmacotherapy teaching. In: Adhikari RK, Jayawickramarajah PT, editors. Essentials of Medical Education. Kathmandu: Health Learning Materials Centre; 1996.

3. Kaufman DM, Mann KV. Achievement of students in a conventional and problem-based learning (PBL) curriculum. Adv Health Sci Educ Theory Pract. 1999;4:245-260.

4. Gitanjali B, Shashindran CH. Curriculum in clinical pharmacology for medical undergraduates of India. Indian J Pharmacol. 2006;38: S108-S114.

5. Flockhart DA, Yasuda SU, Pezzullo JC, Knollmann BC. Teaching rational prescribing: a new clinical pharmacology curriculum for medical students. Naunyn Schmiedebergs Arch Pharmacol. 2002;366:33-43.

6. Orme M, Frolich J, Vrhovac B. Towards a core curriculum in clinical pharmacology for undergraduate medical students in Europe. Eur J Clin Pharmacol. 2002;58:635-640.

7. Vollebregt JA, van Oldenrijk J, Kox D, et al. Evaluation of a pharmacotherapy context-learning programme for preclinical medical students. Br J Clin Pharmacol 2006;62:666-672.
8. Medical Council of India. Graduate Medical Education Regulations. New Delhi: Medical Council of India; 1997.

9. Shankar PR, Dubey AK, Palaian S, Pranaya M, Saha A, Deshpande VY. Favourable student attitudes towards pharmacology in a medical school in Western Nepal. J Int Assoc Med Sci Educ. 2005;156:31-38.

10. Aronson JK, Henderson G, Webb DJ, Rawlins MD. A prescription for better prescribing. BMJ. 2006;333:459-460.

11. Likic R, Maxwell SR. Prevention of medication errors: teaching and training. Br J Clin Pharmacol. 2009;67(6):656-661.

12. Dean B, Schachter M, Vincent C, Barber N. Prescribing errors in hospital inpatients: their incidence and clinical significance. Qual Saf Health Care. 2002;11:340-344.

13. Menon L, Taylor Z, Tuthill DP. Can paediatric junior hospital doctors prescribe competently? Paediatr Perinat Drug Ther. 2006; $7: 118-120$.

14. Oshikoya KA, Senbanjo IO, Amole OO. Interns' knowledge of clinical pharmacology and therapeutics after undergraduate and on-going internship training in Nigeria: a pilot study. BMC Med Educ. 2009;9:50.

15. Tobaiqy M, McLay J, Ross S. Foundation year 1 doctors and clinical pharmacology and therapeutics teaching. A retrospective view in light of experience. Br J Clin Pharmacol. 2007;64:363-372.

16. Heaton A, Webb DJ, Maxwell SRJ. Undergraduate preparation for prescribing: the views of 2413 UK medical students and recent graduates. Br J Clin Pharmacol. 2008;66:128-134.

17. Aston University. Helping New Medical Graduates to Prescribe Safely. Available from: http://www1.aston.ac.uk/about/news/releases/2010/ october/medical-graduates-to-prescribe-safely. Accessed April 20, 2012.

18. DrugInfo. Drug Information Sources. Available from: http://www. drugsrnikolov.com/drugdatabases/druginfosources.html. Accessed on April 20, 2012.

19. Therapeutics Initiative. Sources of drug therapy information. Ther Lett. 2000;35:1-2.

20. Balasubramaniam K. Equitable Pricing, Affordability and Access to Essential Drugs in Developing Countries: Consumers Perspective. Hosbjor: WHO/WTO Secretariat Workshop on Differential Pricing and Financing of Essential Drugs; 2001.

21. Mehta D, editor. British National Formulary 37. London: Pharmaceutical Press; 2002.

22. Grahame-Smith DG, Aronson JK, editors. Oxford Textbook of Clinical Pharmacology and Drug Therapy, 3rd ed. New York: Oxford University Press; 2002:119-126.

23. Gordon M, Chandratilake M, Baker P. Improved junior paediatric prescribing skills after a short e-learning intervention: a randomized controlled trial. Arch Dis Child. 2011;96:1191-1194.

24. Kidd L, Shand E, Beavis R, Taylor Z, Dunstan F, Tuthill D. Prescribing competence of junior doctors: does it add up? Arch Dis Child. 2010;95:219-221.

25. National Medicines Information Centre. Generic prescribing. NMIC Bull. 2009;15:1-6. 


\section{Appendix}

First-year postgraduate doctors' knowledge of clinical pharmacology

and therapeutics

Undergraduate clinical pharmacology and therapeutics (CPT) teaching

1. Were you taught prescription writing in your undergraduate pharmacology?
(a) Yes
(b) No

2. How would you rate your prescribing knowledge as at graduation?
(a) Very poor
(b) Poor
(c) Average
(d) Good
(e) Excellent

3. Do you feel that your undergraduate training has prepared you to prescribe safely?
(a) Yes
(b) No

4. Do you feel that your undergraduate training has prepared you to prescribe rationally?
(a) Yes
(b) No

5. If the above is yes, what other factors may affect your ability to prescribe rationally? (please specify) .........

6. Have you had any specific problems with prescribing during your internship training?
(a) Yes
(b) No

7. If the above is yes, what are the specific problems? (Please specify)

8. Retrospectively, do you think undergraduate CPT teaching should be improved?
(a) Yes
(b) No

9. If the above is yes, please suggest ways of improving the teaching (please specify)

\section{Prescribing information}

10. Are you aware of the Essential Drugs List?
(a) Yes
(b) No

11. If yes, do you prescribe drugs according to the Essential Drugs List?
(a) Yes
(b) No

12. Usually you prescribe by:

(a) Generic names (nonproprietary names)

(b) Trade names (proprietary/brand names)

13. Usually in children you calculate the doses according to the:
(a) Age
(b) Weight
(c) Height
(d) Surface area

14. Usually while prescribing, do you consider the cost of the drugs?
(a) Yes
(b) No

15. Have you been taught to consider the cost of the drugs?
(a) Yes
(b) No

16. Do you understand the term "pharmacoeconomics"?
(a) Yes
(b) No

17. Do you prescribe a newly promoted medicine?
(a) Yes
(b) No

18. Do you prescribe supplemental vitamins and iron preparations?
(a) Yes
(b) No

19. Usually do you prefer a fixed-dose analgesic combination or paracetamol?
(a) Fixed-dose analgesic combination
(b) Paracetamol

20. Have you prescribed under parental influence even when not necessary?
(a) Yes
(b) No

21. Do you routinely check information about drugs before prescribing?
(a) Yes
(b) No

22. If the above is yes, which materials do you consult?
(a) Product insert
(b) Internet
(c) Books/journals
(d) Drug information provided by the medical representatives
(e) Drug information index, eg, CIMS, MIMS, Drug Today, IDR etc
(f) Any other (please specify) 
Advances in Medical Education and Practice

Dovepress

\section{Publish your work in this journal}

Advances in Medical Education and Practice is an international, peerreviewed, open access journal that aims to present and publish research on Medical Education covering medical, dental, nursing and allied healthcare professional education. The journal covers undergraduate education, postgraduate training and continuing medical education including emerging trends and innovative models linking education, research, and healthcare services. The manuscript management system is completely online and includes a very quick and fair peer-review system. Visit http://www.dovepress.com/testimonials.php to read real quotes from published authors.

Submit your manuscript here: http://www.dovepress.com/advances-in-medical-education-and-practice-journal 